\title{
Connexin 32 downregulation is critical for chemoresistance in oxaliplatin-resistant HCC cells associated with EMT
}

This article was published in the following Dove Press journal: Cancer Management and Research

\author{
Yan Yang' \\ Jing-Hao Yao' \\ Qian-Yu Du' \\ Yong-Chun Zhou ${ }^{2}$ \\ Ting-Jing $\mathrm{Yao}^{3}$ \\ Qiong $\mathrm{Wu}^{4}$ \\ Jing Liu' \\ Yu-Rong Ou ${ }^{4}$
}

'Department of Medical Oncology, The First Affiliated Hospital of Bengbu Medical College, Bengbu 233004, People's Republic of China; ${ }^{2}$ Department of Radiation Oncology, The First Affiliated Hospital of Bengbu Medical College, Bengbu 233004, People's Republic of China; ${ }^{3}$ Department of Surgical

Oncology, The First Affiliated Hospital of Bengbu Medical College, Bengbu 233004, People's Republic of China; ${ }^{4}$ Department of Pathology, The First Affiliated Hospital of Bengbu Medical College, Bengbu 233004, People's Republic of China
Correspondence: Yan Yang Department of Medical Oncology, The First Affiliated Hospital of Bengbu Medical College, No. 287 Changhuai Road, Longzihu District, Bengbu, Anhui 233004,

People's Republic of China

Tel +865523074480

Fax +865523074480

Email qiannianhupo@।63.com

Yu-Rong Ou

Department of Pathology, The First Affiliated Hospital of Bengbu Medical College, No. 287 Changhuai Road,

Longzihu District, Bengbu, Anhui 233004

People's Republic of China

Tel +86 5523070209

Fax +865523070209

Email snowyc1220@163.com
Background: Oxaliplatin (OXA)-based chemotherapy is critical in the management of advanced hepatocellular carcinoma (HCC); however, acquired drug resistance has largely restricted its clinical efficacy. This study aims to explore the key mechanisms and regulatory factors determining chemosensitivity in HCC.

Methods: We developed OXA-resistant (OR) HCC cells and used multiple methods, including real-time RT-PCR, Western blot, immunofluorescence, transwell invasion assay, wound-healing assay, MTT assay, gene transfection, and immunohistochemistry to achieve our goals

Results: We found that OR HCC cells showed a typical epithelial-mesenchymal transition (EMT) phenotype. Meanwhile, the expression of $\mathrm{Cx} 32$, a major member of the liver connexin $(\mathrm{Cx})$ family, was lowly expressed in OR HCC cells. Downregulation of $\mathrm{Cx} 32$ in parental HCC cells led to EMT induction and thereby reduced OXA cytotoxicity, while $\mathrm{Cx} 32$ upregulation in OR HCC cells could reverse the EMT phenotype and partially restore chemosensitivity to OXA. Finally, in human HCC tissue samples, Cx32 was positively correlated with the expression of the EMT marker E-cadherin and negatively correlated with the expression of Vimentin.

Conclusion: Our findings demonstrated that downregulation of $\mathrm{Cx} 32$ may be an important determinant for HCC cells to acquire EMT-related acquired drug resistance to OXA, and targeting Cx32 could be a novel strategy to overcome OXA resistance in HCC.

Keywords: hepatocellular carcinoma, oxaliplatin chemoresistance, connexin32, epithelialmesenchymal transition

\section{Introduction}

Hepatocellular carcinoma (HCC) is the fourth common malignancy worldwide, ${ }^{1}$ with characteristics of high aggressivity and poor prognosis. Hepatocarcinogenesis is concealed, and early diagnosis of HCC is difficult. Most HCC patients cannot undergo curative surgery due to locally extensive invasion or distant metastasis at the time of diagnosis. In recent years, targeted therapy and immunotherapy have improved the prognosis of patients with advanced HCC. ${ }^{2}$ However, their clinical benefits remain moderate, especially with the lack of effective predictive indicators, resulting in unsatisfactory efficacy in clinical practice. With the application of third-generation cytotoxic drugs, systemic chemotherapy is making a breakthrough in the treatment of advanced HCC. Specifically, oxaliplatin (OXA)-based systemic chemotherapy has become one of the most important options for advanced HCC. ${ }^{3,4}$ However, patients 
using platinum drugs often suffer from drug resistance during the clinical application, ${ }^{5}$ and the mechanisms underlying drug resistance remain largely unknown.

Epithelial-mesenchymal transition (EMT) refers to the process by which epithelial cells switch to mesenchymal cells through specific processes and is associated with chemoresistance, including to platinum drugs. ${ }^{6}$ Studies have revealed that cancer cells acquire the mesenchymal phenotype in the process of generating acquired drug resistance, and tumor cells in the mesenchymal differentiation state often exhibit the characteristics of primary drug resistance. ${ }^{7}$ Our previous study confirmed phenotypic changes consistent with the EMT phenotype in gemcitabine (GEM)-resistant HCC cells. ${ }^{8}$ It is generally recognized that during EMT, epithelial cells lose epithelial properties and acquire the characteristics of mesenchymal cells, resulting in decreased intercellular adhesion and increased cell motility and invasion capacities. At the molecular level, cells lowly express or lose epithelial markers such as E-cadherin and highly express mesenchymal molecular markers, including Vimentin and $\mathrm{N}$-cadherin, with upregulation of transcription factors such as Snail, Slug, and Twist. ${ }^{9}$

Connexin (Cx) is the basic unit of gap junction (GJ), which communicates the cytoplasm of two adjacent cells by directly mediating the transmission of electrical, chemical, and metabolic substances, thereby playing important roles in a series of life events, including cellular activity synchronization, tissue homeostasis maintenance, and cell proliferation and apoptosis. ${ }^{10}$ Abnormal $\mathrm{Cx}$ and GJ levels are closely related to the occurrence and development of various tumors, including HCC. ${ }^{11} \mathrm{Cx} 32$, forming $90 \%$ of hepatic GJs, is the major Cx isoform expressed in the liver. ${ }^{12}$ This gene was originally considered a tumorsuppressor gene $\mathrm{g}^{13,14}$ and has been demonstrated to be implicated in multiple hepatocellular processes such as carcinogenesis, cell proliferation, apoptosis, invasion, and metastasis. ${ }^{15-18}$ More importantly, Cx32 can affect sensitivity to many chemotherapeutic drugs, including platinum drugs. ${ }^{19,20}$

In the current study, we successfully established three OXA-resistant (OR) HCC cell lines and found that they all acquired EMT characteristics. Meanwhile, among the three Cxs (Cx26, Cx32, and Cx43) expressed in the liver, Cx32 was the most remarkably downregulated protein during the process of drug resistance. Downregulation of $\mathrm{Cx} 32$ in parental HCC cells induced EMT and decreased OXA cytotoxicity, while overexpression of $\mathrm{Cx} 32$ in OR HCC cells reversed the mesenchymal phenotype and partially restored sensitivity to OXA. Finally, we further confirmed the associations of $\mathrm{Cx} 32$ with the EMT markers E-cadherin and Vimentin in human HCC tissue samples. These results indicated that downregulation of $\mathrm{Cx} 32$ is involved in OXA-resistance and EMT features of HCC cells, demonstrating that targeting $\mathrm{Cx} 32$ may provide a new strategy for overcoming $\mathrm{HCC}$ resistance to OXA.

\section{Material and methods}

\section{Cell lines and culture}

The human HCC HepG2, Huh7, and SMMC-7721 cell lines were purchased from the cell bank of the Shanghai Institutes for Biological Sciences (Shanghai, China) and cultured at $37^{\circ} \mathrm{C}$ in $5 \% \mathrm{CO}_{2}$ in Dulbecco's modified Eagle's medium (DMEM, Invitrogen, Carlsbad, CA, USA) supplemented with 10\% FBS (HyClone Laboratories, Inc., Logan, UT, USA), 100 U/mL penicillin (Gibco, Waltham, MA, USA), and $100 \mu \mathrm{g} / \mathrm{mL}$ streptomycin (Gibco).

\section{Establishment of OR HCC cell lines}

To develop HCC cell lines chronically resistant to OXA, the human HCC cell lines HepG2, Huh7, and SMMC-7721 were continuously exposed to increasing doses of OXA for at least 6 months. A small dose of OXA was used as the starting point, to ensure that surviving cells can exceed $70 \%$ confluency. After the resultant cells grew stably in the medium containing OXA, they were passaged by trypsinization and exposed to a higher concentration of OXA. The process was repeated until the resultant cells could grow stably in the medium with the indicated OXA concentration. By using this concentration increment method, ${ }^{21}$ three OR HCC cell lines displaying resistance to the growth inhibitory properties of OXA at the indicated concentrations were established.

\section{Cell growth assessment by the MTT assay} Parental and OR HCC cells $\left[(8-10) \times 10^{3} /\right.$ well $]$ were seeded at equal densities into 96-well culture plates for overnight incubation. OXA at different concentrations was then added for $24 \mathrm{hrs}$. MTT assay was performed as described previously. ${ }^{22}$

\section{Western blot and qRT-PCR}

Western blot, RNA isolation, and qRT-PCR assay were described in our previous studies. ${ }^{18,22}$ Primary antibodies and dilutions used for Western blot were: P-gp (1:500; Proteintech Group, Inc., Rosemont, IL, USA); breast cancer resistance 
protein (BCRP) $(1: 1,000 ;$ CST, Danvers, MA, USA); E-cadherin (1:1,000; Abcam, Cambridge, MA, USA); Vimentin (1:1,000; Abcam); Snail (1:1,000; Abcam); Slug (1:2,000; Abcam); Cx26 (1:500; Invitrogen); Cx32 (1:500; Sigma-Aldrich, St. Louis, MO, USA); Cx43 (1:2,000; SigmaAldrich); and $\beta$-actin (1:500; Santa Cruz Biotechnology, Santa Cruz, CA, USA). The primers used for qRT-PCR are listed in Table 1. Gene and protein expression levels were normalized to those of the internal controls (GAPDH or $\beta$-actin).

\section{Immunofluorescence}

Immunofluorescence was performed as described previously. ${ }^{18,22}$ Primary antibodies targeting Cx32, E-cadherin, and Vimentin were used at 1:200 in 2\% BSA. Alexa 488- or 568-conjugated secondary antibodies were added for $1 \mathrm{hr}$ in the dark at room temperature. The cells were examined and photographed under a fluorescence microscope (Olympus, Tokyo, Japan).

\section{Expression plasmids and gene silencing}

The $\mathrm{pEX}-2$ plasmid containing the full-length cDNA of human Cx32 (Gene ID: 2705) was purchased from Suzhou GenePharma Co., Ltd. (Suzhou, China). The empty plasmid pEX-2 was used as a negative control (NC). Cx32 siRNA fragments were also synthesized and supplied by GenePharma. The specific siRNA sequences for Cx32 and NC were described in our previous report. ${ }^{18}$ The transfection reagent was Lipofectamine ${ }^{\mathrm{TM}} 2000$ (Invitrogen), and experiments were conducted strictly according to the manufacturer's instructions.

\section{Transwell invasion and wound healing assays}

Transwell invasion and wound-healing assays to determine the invasion and migration capabilities of HCC cells were performed as described previously. ${ }^{8,18}$

\section{Immunohistochemistry}

A total of 34 paired samples of human HCC and matched adjacent non-cancerous tissues were collected as previously described. $^{18}$ Anti-Cx32 (1:100, Sigma-Aldrich), antiE-cadherin (1:50, Abcam), and anti-Vimentin (1:100, Abcam) primary antibodies were used for immunohistochemistry according to a two-step protocol. The intensity of positive signals was scored as: 0 , negative (no staining); 1 , weak (light yellow); 2, moderate (yellowish brown); 3, strong (brown). The extent of positivity was scored based on the percentage of positive cells: $0,<5 \% ; 1,5 \sim 25 \% ; 2,26 \sim 50 \% ; 3,>50 \%$. The staining index (SI) was determined as the final score by multiplying the above subscores and classified as negative (score $0-1), 1+$ (score $2-3), 2+$ (score $4-5$ ), or $3+$ (score $\geq 6$ ). The study methodologies conformed to the standards set by the Declaration of Helsinki and were approved by the Ethics Committee of our institution. Written informed consent was obtained from the patients or their immediate family members.

\section{Statistical analysis}

All statistical analyses were performed with the SPSS version 19.0 statistical software (Chicago, IL, USA). Numerical data are mean \pm SD and were compared by unpaired Student's $t$-test. Differences between two groups in immunohistochemistry were evaluated by the Chisquare test or Wilcoxon rank test as appropriate. Spearman's correlation was used to analyze the association of expressions of Cx32 and EMT markers. $P<0.05$ was considered statistically significant.

\section{Results}

\section{Identification of OR HCC cell lines}

In order to better simulate the clinical occurrence of acquired drug resistance to OXA, HepG2, Huh7, and

Table I The primers used for qRT-PCR analysis

\begin{tabular}{|c|c|c|c|}
\hline \multirow[t]{2}{*}{ Gene } & \multicolumn{2}{|l|}{ Sequence } & \multirow[t]{2}{*}{ Product size (bps) } \\
\hline & Sense $\left(5^{\prime}-3^{\prime}\right)$ & Antisense ( $\left.5^{\circ}-3^{6}\right)$ & \\
\hline $\mathrm{C} \times 26$ & GCTGCAAGAACGTGTGCTAC & TGGGTTTTGATCTCCTCGAT & 196 \\
\hline $\mathrm{C} \times 32$ & TCCCTGCAGCTCATCCTAGT & CCCTGAGATGTGGACCTTGT & 156 \\
\hline Cx43 & GGTCTGAGTGCCTGAACTTGCCT & AGCCACACCTTCCСTCCAGCA & 184 \\
\hline E-cadherin & GAAGTGTCCGAGGACTTTGG & CAGTGTCTCTCCAAATCCGATA & 109 \\
\hline Vimentin & TGTCCAAATCGATGTGGATGTTTC & TTGTACCATTCTTCTGCCTCCTG & 117 \\
\hline$\beta$-actin & TCCTCCTGAGCGCAAGTACTC & GCATTTGCGGTGGACGAT & 130 \\
\hline
\end{tabular}

Abbreviation: $\mathrm{Cx}$, connexin. 
SMMC-7721 cells displaying resistance to the growth inhibitory properties of OXA at concentrations of $5 \mu \mathrm{g} /$ $\mathrm{mL}, 4 \mu \mathrm{g} / \mathrm{mL}$, and $8 \mu \mathrm{g} / \mathrm{mL}$, respectively, were eventually developed by concentration increment method as described in the "Material and methods" section. The resulting cells were designated as OR HCC cells, including HepG2/OXA, Huh7/OXA, and SMMC-7721/OXA. The drug-resistance features of these OR HCC lines were subsequently identified. MTT results showed that compared with the parental HCC cell lines, the growth inhibitory effect of OXA on OR HCC cells was significantly decreased (Figure 1A-C), and the expression levels of drug-related proteins P-gp and BCRP were significantly upregulated (Figure 1D-F). These results indicated that OR HCC cell lines were successfully established and could be used for subsequent drug-resistance studies.

\section{EMT changes in OR HCC cells}

Compared with the parental HCC cell lines, OR HCC cells showed typical EMT characteristics, with elongated spindle shape, loss of cell polarity, and increased formation of pseudopodia (Figure 2A-C). While the epithelial marker E-cadherin was downregulated at the mRNA level, the mesenchymal marker Vimentin was upregulated (Figure 2D). At the protein level, similar changes were observed (Figure 2E-G). Using the Huh7 cell line as an example, immunofluorescence further confirmed a decrease in the fluorescence intensity of E-cadherin but an increase in that of Vimentin in Huh7/OXA cells (Figure 2H). Thus, OR HCC cells acquired an EMT phenotype.

\section{Increased invasion and migration activity in OR HCC cells}

High invasion and migration abilities are important characteristics of tumor cells that undergo EMT. To further confirm the EMT progress in OR HCC cells, we subsequently performed the transwell invasion assay. The results showed significantly more OR HCC cells invading into the lower chamber compared with the parental HCC cells (Figure 3A-C). Consistently, OR HCC cells also had significantly enhanced migratory activity in vitro as evidenced by the wound-healing assay (Figure 3D-F).

\section{Downregulation of $\mathrm{C} \times 32$ in OR HCC cells}

To assess the role of $\mathrm{Cxs}$ in the drug resistance of $\mathrm{HCC}$ cells to OXA, we detected the expression and distribution of
Cx26, Cx32, and $\mathrm{Cx} 43$ in parental and resistant $\mathrm{HCC}$ cells. The results of qRT-PCR and Western blot showed that Cx 43 expression was not significantly altered, while $\mathrm{C} \times 26$ and Cx32 levels were reduced in OR HCC cells compared with the respective parental cells. Most importantly, downregulation of Cx32 was the most obvious (Figure 4A-C). Subsequently, immunofluorescence revealed that $\mathrm{Cx} 32$ fluorescence was significantly decreased in SMMC-7721/OXA cells compared with parental SMMC7721 cells, and Cx32 signals were mainly located in the cytoplasm (Figure 4D). These results indicated that $\mathrm{Cx} 32$ may be associated with OXA-induced EMT in HCC cells.

\section{Downregulation of $\mathrm{C} \times 32$ induces EMT in HCC parental cells}

To further investigate the role of $\mathrm{Cx} 32$ in OR HCC cells with EMT features, we first explored whether Cx32 silencing by its specific siRNA could induce EMT in parental cells. Since the effect of $\mathrm{Cx} 32$ on EMT procedure in HepG2 and SMMC-7721 parental cells was described in our previous report, ${ }^{18}$ we continued to use the Huh7 cell line as a tool to confirm whether $\mathrm{Cx} 32$ universally exerts this effect in the current study. Western blot analysis confirmed a decreased $\mathrm{Cx} 32$ expression in Huh7 cells transfected with specific Cx32 siRNAs, with siRNA3 exhibiting the most inhibition (Figure 5A); thus, Cx32 siRNA3 was used in the following gene silencing experiments. As shown in Figure 5B, irregular fibroblastoid morphologic changes were observed in Huh7 cells upon Cx32 downregulation. Meanwhile, the expression level of the epithelial marker E-cadherin was decreased, while those of the mesenchymal markers Vimentin and Snail were increased (Figure 5C). The invasive ability of Huh7 cells was markedly enhanced by $\mathrm{Cx} 32$ downregulation as assessed by transwell invasion assay (Figure 5D). In addition, downregulation of $\mathrm{Cx} 32$ by siRNA significantly reduced the inhibitory effect of OXA in Huh7 cells (Figure 5E). Taken together, these results suggested that parental HCC cells with depleted Cx32 generally exhibited the phenotypic characteristics of EMT and were less sensitive to chemotherapy with OXA.

\section{Upregulation of $\mathrm{C} \times 32$ reverses EMT in OR HCC cells}

We next assessed whether specific upregulation of $\mathrm{Cx} 32$ by cDNA gene transfection could reverse EMT in OR HCC cells. We found that Huh7/OXA and SMMC-7721/OXA 
A

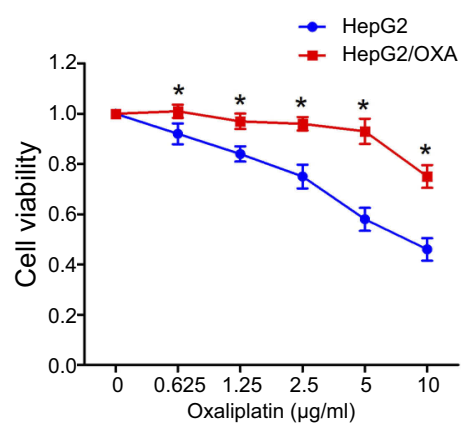

B

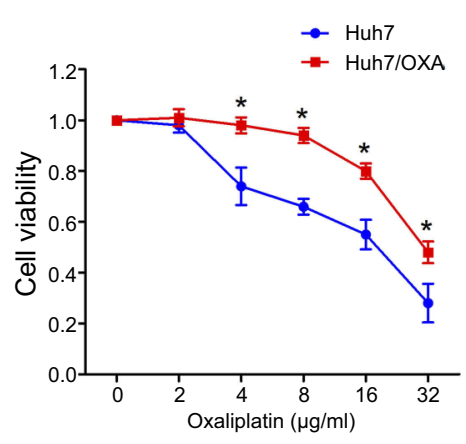

C

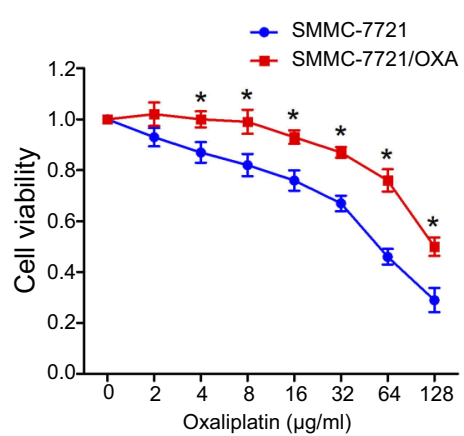

Figure I Establishment and identification of oxaliplatin-resistant (OR) HCC cell lines. (A-C) Parental HepG2, Huh7, SMMC-772I cells, and respective OR cells, including HepG2/OXA, Huh7/OXA, and SMMC-772I/OXA, were exposed to different concentrations of OXA for 24 hrs. Then, cell viability was detected by the MTT assay. The value of controls, treated with no oxaliplatin, was set at I.0. (D-F) Induction of cell resistance markers in OR HCC cells, assessed by Western blot for P-gP and BCRP. Data obtained by densitometry represent the mean \pm SD of target protein/GAPDH band densities of three determinations for each treatment condition. OR HCC cells were cultured in cell growth medium containing $5 \mu \mathrm{g} / \mathrm{mL}, 4 \mu \mathrm{g} /$ $\mathrm{mL}$, and $8 \mu \mathrm{g} / \mathrm{mL}$ OXA for HepG2, Huh7, and SMMC-772I, respectively. $* P<0.05$, and $* * P<0.01$ vs parental control.

Abbreviations: BCRP, breast cancer resistance protein; OXA, oxaliplatin; P-gp, pglycoprotein; SMMC, SMMC-772I.

cells overexpressing Cx32 displayed a round cell-like morphology (Figure 6A). Moreover, E-cadherin expression was significantly increased, while Vimentin and Snail were significantly downregulated (Figure 6B). As expected, we found that upregulation of $\mathrm{Cx} 32$ markedly reduced invasive ability (Figure 6C) and partially restored OXA chemosensitivity (Figure 6D) in both Huh7/OXA and SMMC-7721/ OXA cells. Altogether, these findings indicated that decreased $\mathrm{Cx} 32$ is involved in OXA resistance associated with EMT in HCC cells.

\section{Expression of $\mathrm{C} \times 32$, E-cadherin, and Vimentin in HCC tissues and adjacent nontumor tissues}

Cx32 was abundantly expressed in the cell membrane in adjacent nontumor (ANT) tissues, but showed low and ectopic expression in the cytoplasm in HCC tissues $\left(\chi^{2}=14.233\right.$, $P=0.000$ ) (Figure 7A). E-cadherin membranous expression rate in ANT tissues was as high as $94.1 \%$ (32/34), while in HCC its expression decreased to $70.6 \%(24 / 34)$ with overt membrane loss $\left(\chi^{2}=6.476, P=0.023\right)$ (Figure 7A). Vimentin was almost not expressed in ANT tissues, but its positive expression rate in HCC tissues was $61.8 \%$ (21/34) $\left(\chi^{2}=18.281, P=0.000\right)$ (Figure 7A). Differences in expression intensities of the above three indicators between HCC and ANT tissues were significant (Table 2). As for the quantitative SI, Cx32 and E-cadherin were concomitantly lower while Vimentin was higher in HCC tissues compared with ANT tissues (Figure 7B-D). Cx32 expression was demonstrated to be positively correlated with E-cadherin in HCC tissues by our previous study. ${ }^{18}$ In the present study, Cx32 expression was negatively associated with Vimentin expression as assessed by Spearman correlation analysis (Table 3). Taken together, these findings suggested tight regulatory relationships among Cx32, E-cadherin, and Vimentin during hepatocarcinogenesis.

\section{Discussion}

The treatment of unresectable locally advanced and metastatic HCC represents a challenge in the clinical practice. The prognosis of this patient population is extremely poor, and median overall survival remains only few months. ${ }^{23}$ Palliative chemotherapy, especially OXAbased systemic chemotherapy, is critical in the management of advanced HCC. ${ }^{3,4}$ However, OXA still inevitably encounters drug resistance in clinical application. ${ }^{5,24}$ Therefore, it is urgent to explore the mechanism underlying drug resistance to OXA in $\mathrm{HCC}$, providing a theoretical basis for clinical rational use and overcoming drug resistance. 
A

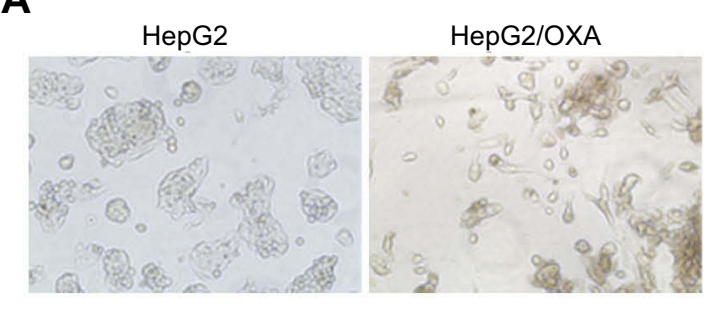

B

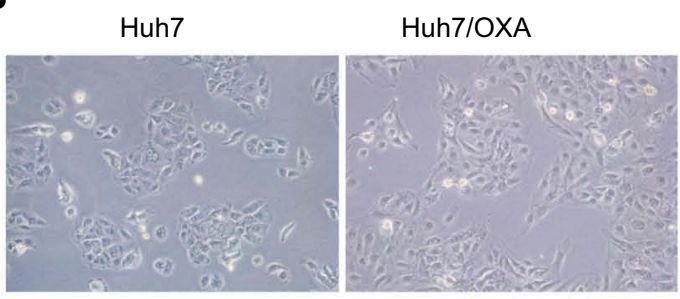

C

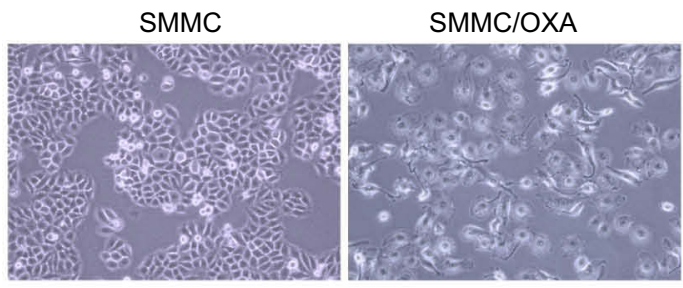

E

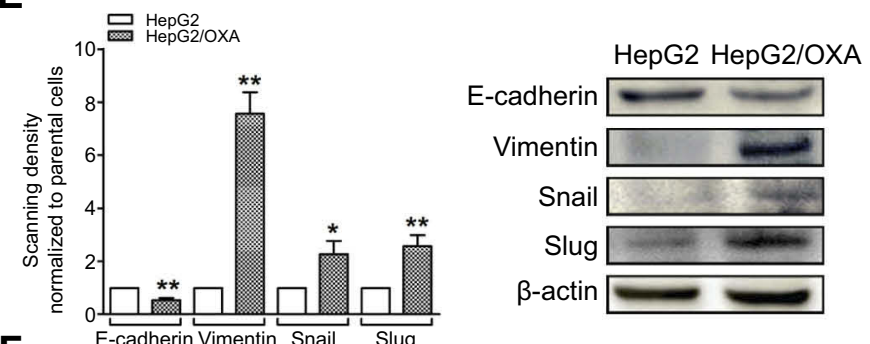

F

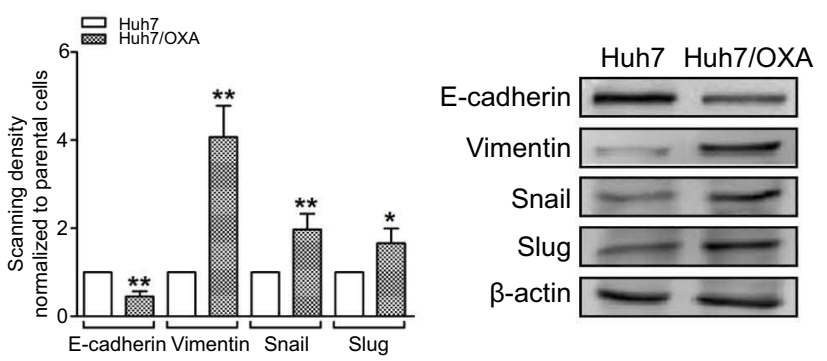

G

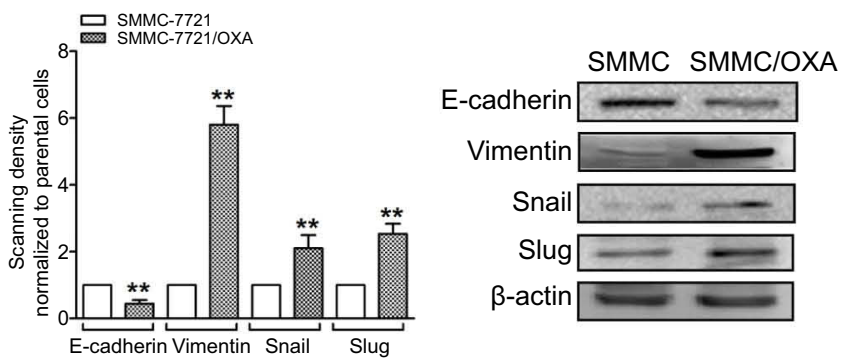

D
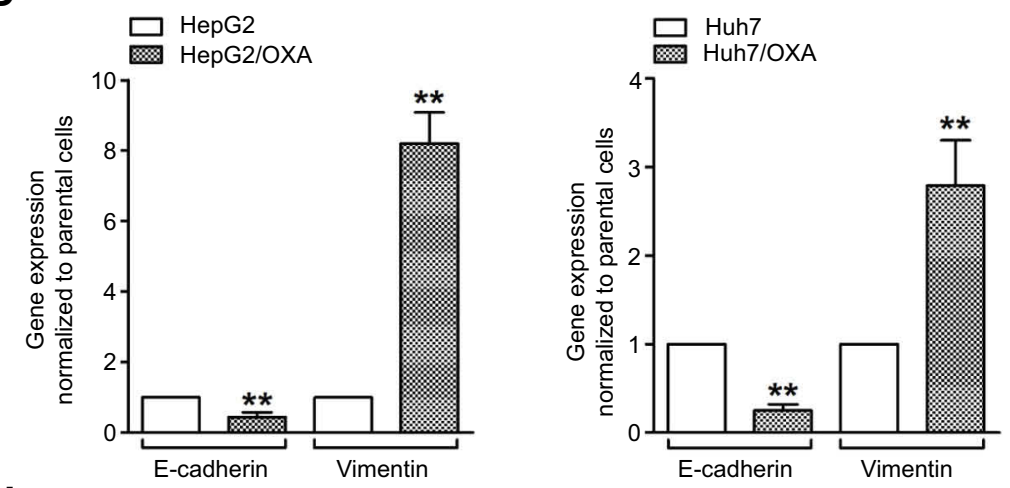

H
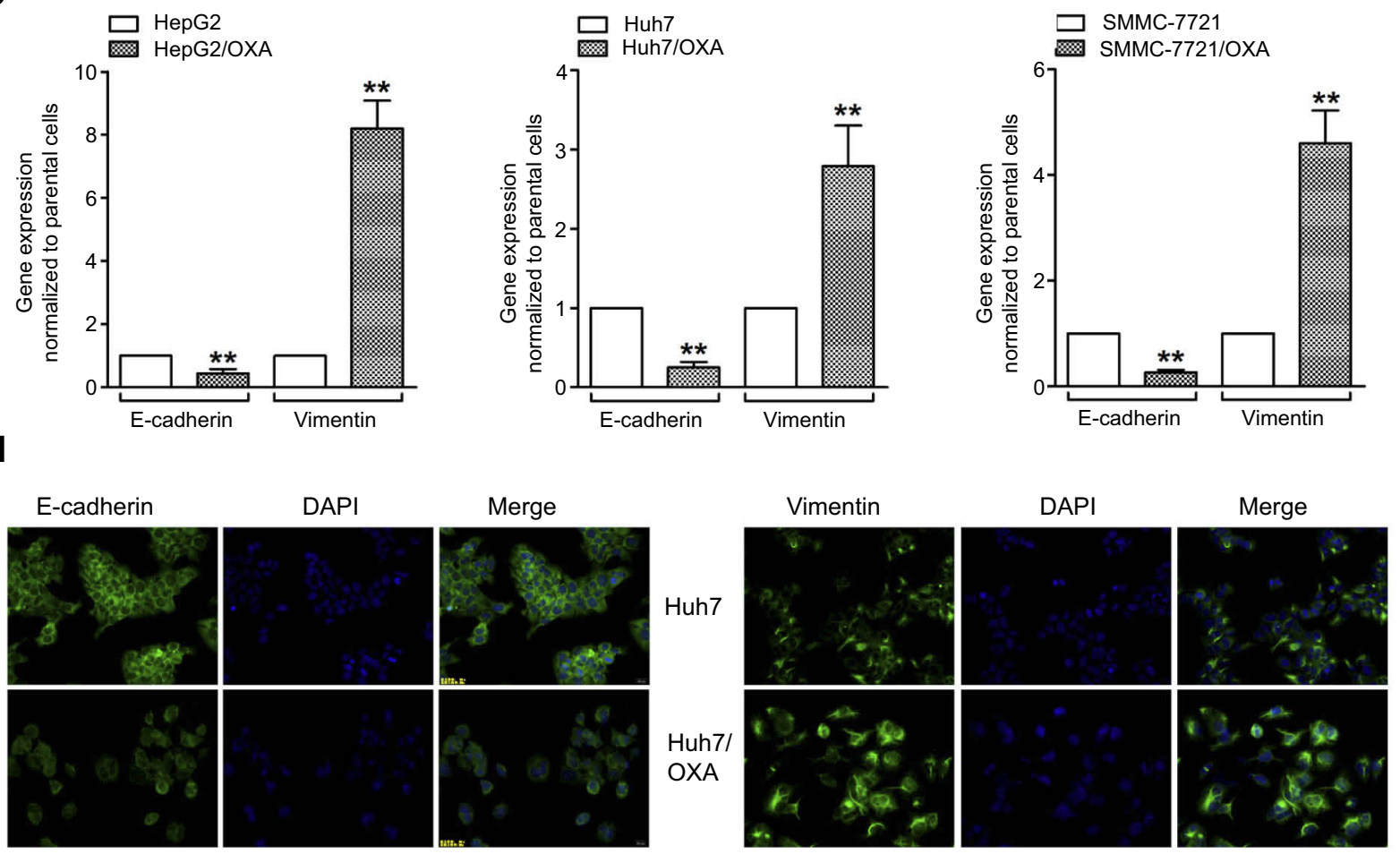

Figure 2 OR HCC cells acquire the EMT phenotype. (A-C) Morphological changes of HepG2/OXA, Huh7/OXA, and SMMC-772I/OXA cells compared with parental counterparts, as assessed by microscopy. (D) qRT-PCR was performed to assess the mRNA levels of E-cadherin and Vimentin in parental and OR HCC cells. (E-G) Left panel, Western blot was conducted to measure the protein expression levels of E-cadherin, Vimentin, Snail, and Slug in parental and OR HCC cells. Right panel, quantitative results for the left panel. (H) Huh7/OXA cells expressed low level of E-cadherin but high level of Vimentin compared with parental Huh7 cells as evidenced by immunofluorescent staining (original magnification, $\times 200$ ). OR HCC cells were cultured in cell growth medium containing $5 \mu \mathrm{g} / \mathrm{mL}, 4 \mu \mathrm{g} / \mathrm{mL}$, and $8 \mu \mathrm{g} / \mathrm{mL}$ OXA for HepG2, Huh7, and SMMC-772I, respectively. $* P<0.05$, and $* * P<0.01$ vs parental control.

Abbreviations: EMT, epithelial-mesenchymal transition; HCC, hepatocellular carcinoma; OR, OXA-resistant; OXA, oxaliplatin. 
A

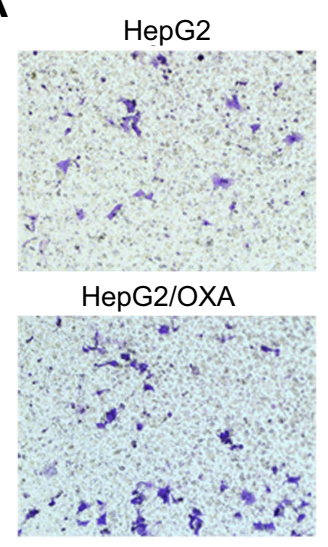

B

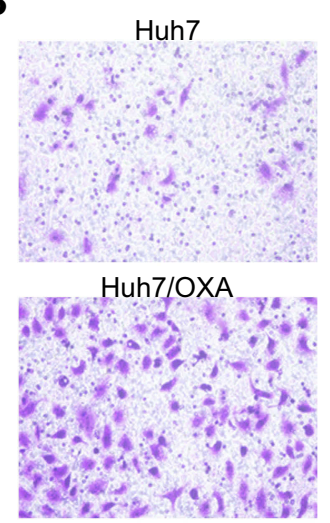

C

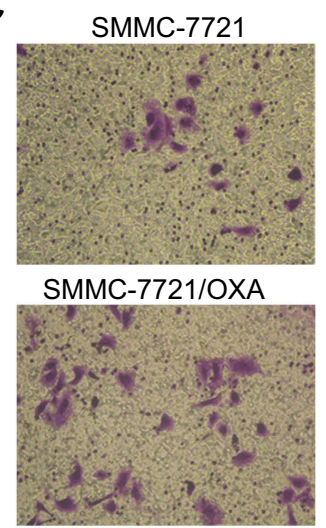

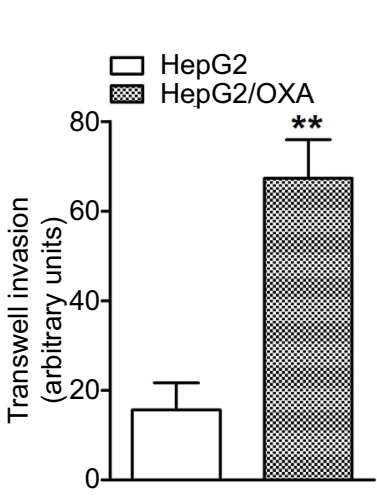
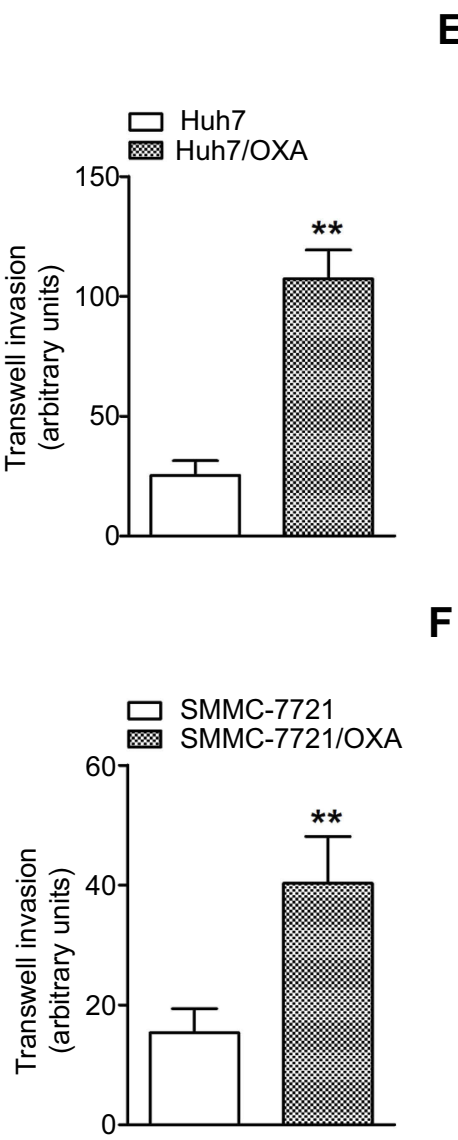

E

$\mathbf{F}$
D
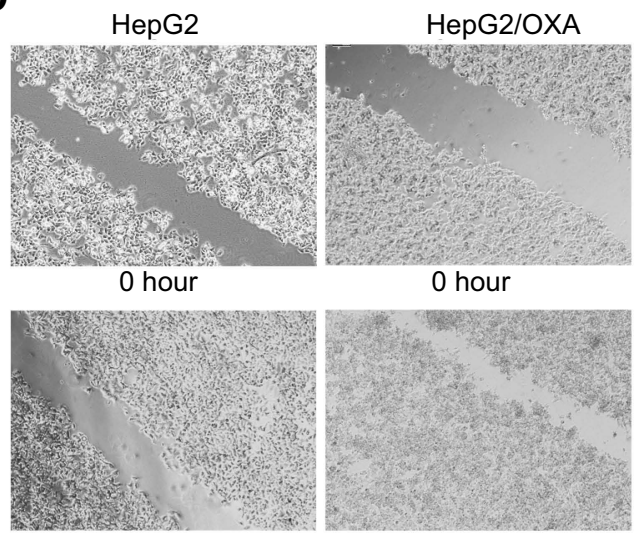

24 hour
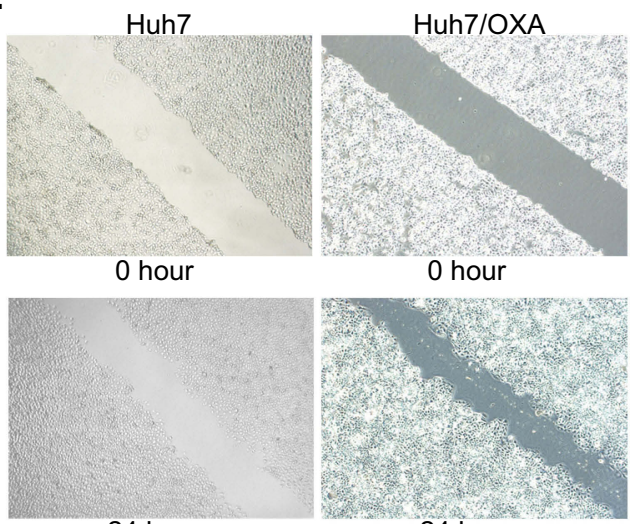

24 hour

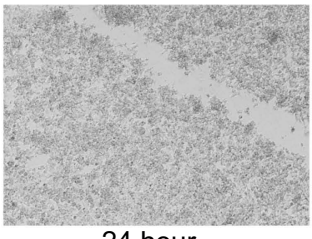

24 hour
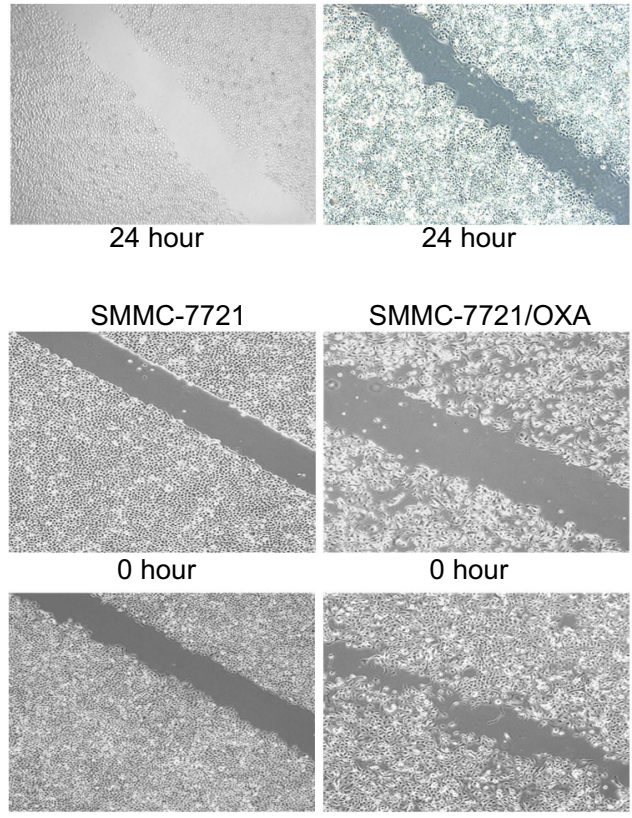

24 hour
SMMC-7721/OXA

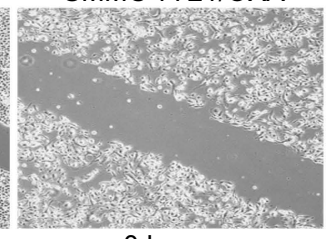

0 hour

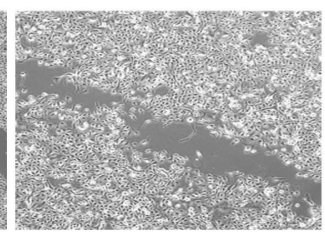

24 hour

Figure 3 OR HCC cells show increased invasion and migratory abilities. (A-C) The transwell assay was performed to measure the invasive abilities of HepG2/OXA, Huh7/ OXA, and SMMC-772I/OXA cells compared with parental counterparts. (D-F) The wound-healing assay was performed to compare the migratory potential of HepG2 and HepG2/OXA cells, Huh7 and Huh7/OXA cells, SMMC-772I and SMMC-7721/OXA cells, and the distance migrated was measured. OR HCC cells were cultured in cell growth medium containing $5 \mu \mathrm{g} / \mathrm{mL}, 4 \mu \mathrm{g} / \mathrm{mL}$, and $8 \mu \mathrm{g} / \mathrm{mL}$ OXA for HepG2, Huh7, and SMMC-772I, respectively. $* * P<0.01$ vs parental control.

Abbreviations: HCC, hepatocellular carcinoma; OR, OXA-resistant; OXA, oxaliplatin.

Increasing evidence has demonstrated that EMT is closely related to drug resistance in human tumors (including HCC). Yang et al developed OR colorectal cancer cells using the concentration increment method and observed a mesenchymal invasive phenotype consistent with EMT. ${ }^{21}$ Adriamycin induces EMT in breast cancer cells in vitro; however, only cells with EMT features exhibit high invasion ability and multidrug resistance. ${ }^{25}$ Subsequently, typical EMT phenotypic changes were observed in non-small cell lung cancer (NSCLC) cells 
A
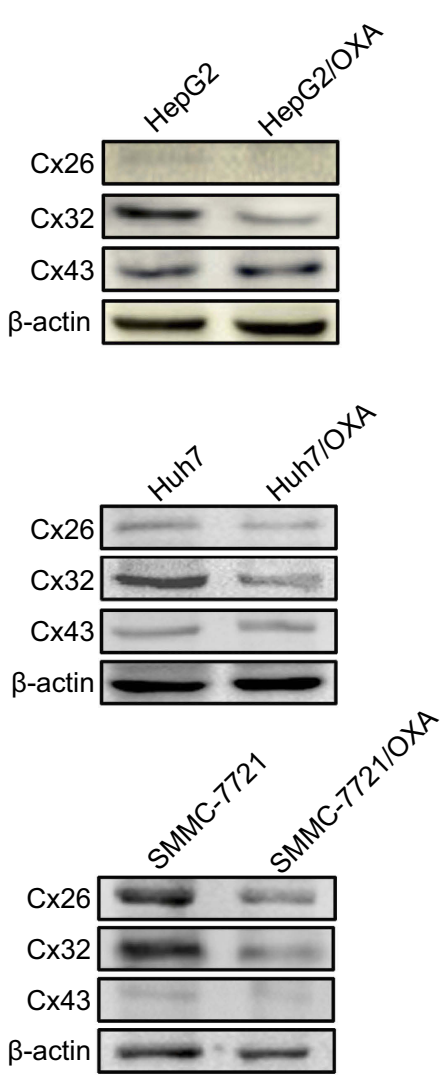

D

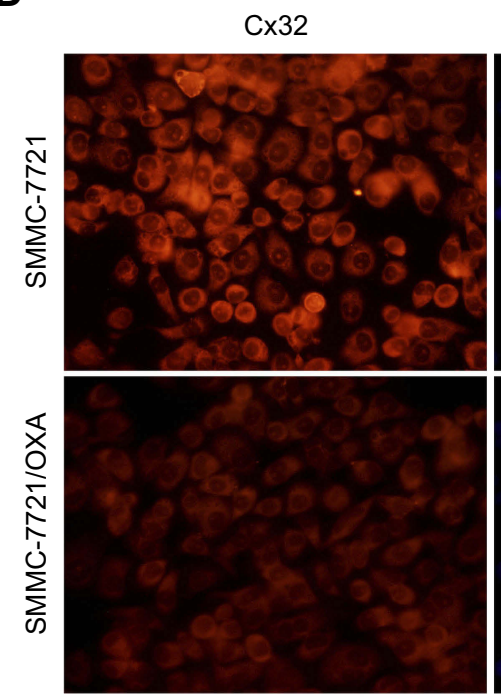

B

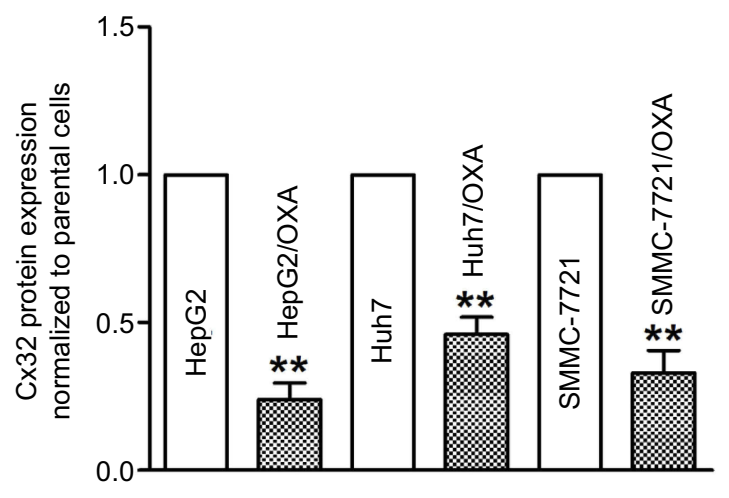

C

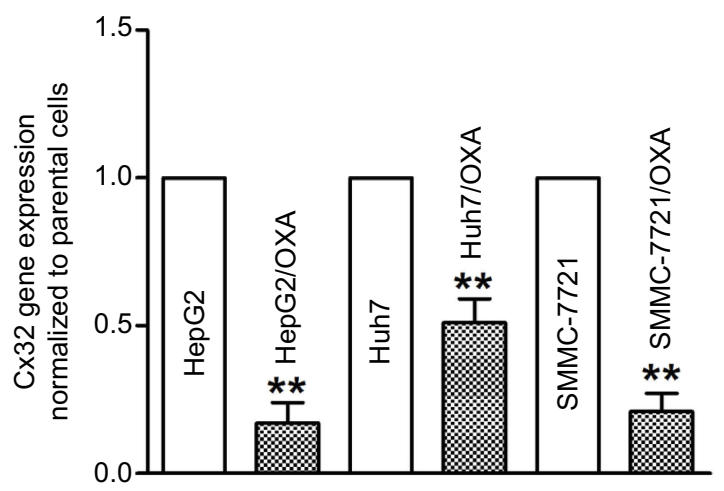

DAPI
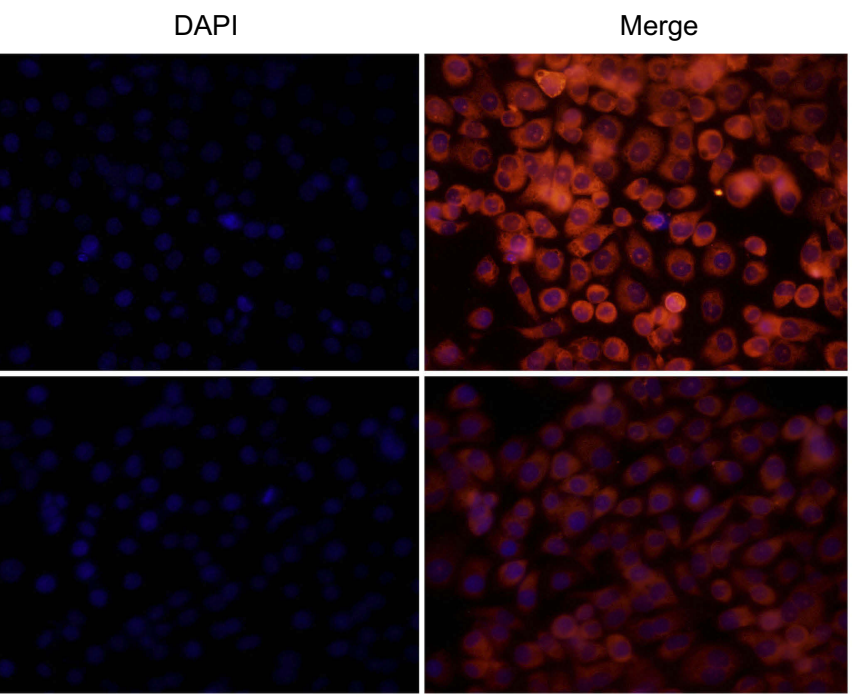

Figure 4 OR HCC cells exhibit low expression of Cx32. (A) Western blot was performed to assess protein expression levels of Cx26, Cx32, and Cx43 in parental HepG2, Huh7, SMMC-772I cells, and OR counterpart cells. (B) Quantitative results for Cx32 protein expression. Bar graphs were derived from densitometric scanning of blots for Cx32. (C) Decreased mRNA level of Cx32 was detected in OR HCC cells compared with parental HCC cells, as shown by qRT-PCR. (D) Immunofluorescent staining revealed decreased expression of $\mathrm{C} \times 32$, by showing that weaker fluorescence intensities for positive signals were observed, in SMMC-772I/OXA cells compared with parental SMMC-772I cells (original magnification, $\times 200$ ). OR HCC cells were cultured in cell growth medium containing $5 \mu \mathrm{g} / \mathrm{mL}, 4 \mu \mathrm{g} / \mathrm{mL}$, and $8 \mu \mathrm{g} / \mathrm{mL}$ OXA for HepG2, Huh7, and SMMC-772I, respectively. $* * P<0.01$ vs parental control.

Abbreviations: Cx, connexin; HCC, hepatocellular carcinoma; OR, OXA-resistant; OXA, oxaliplatin.

resistant to cisplatin ${ }^{26}$ and docetaxel, ${ }^{27} \mathrm{HCC}$ cells resistant to doxorubicin $^{28}$ and $\mathrm{GEM}^{8}{ }^{8}$ glioma cells resistant to temozolomide, ${ }^{29}$ and ovarian cancer cells resistant to cisplatin. ${ }^{30}$ Management strategies, including direct overexpression of E-cadherin, ${ }^{31}$ inhibition of the EMTrelated transcription factor $\mathrm{Zeb1},{ }^{27}$ and targeted knockout of Slug, ${ }^{32}$ could reverse the mesenchymal state of drugresistant cells and restore sensitivity to antitumor therapy. 
A
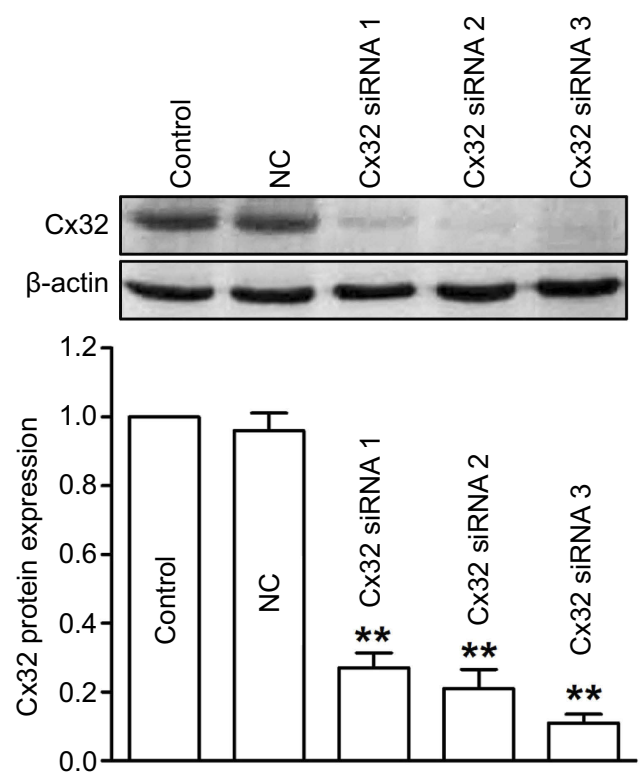

D

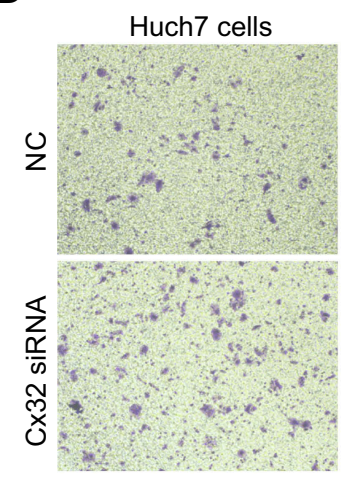

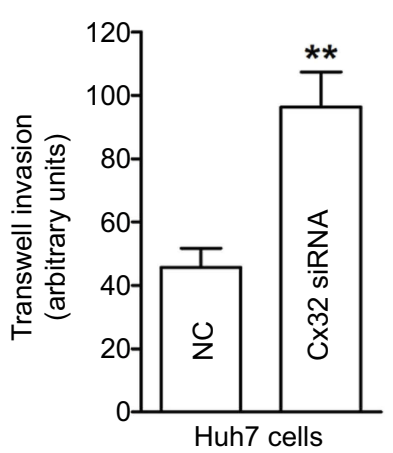

B

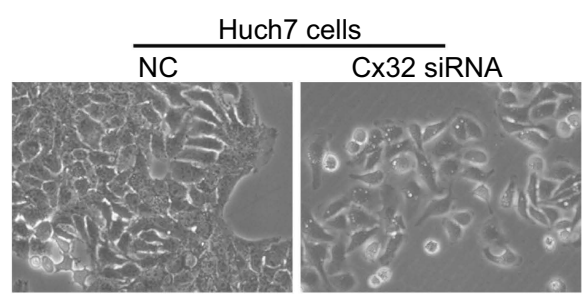

C

E

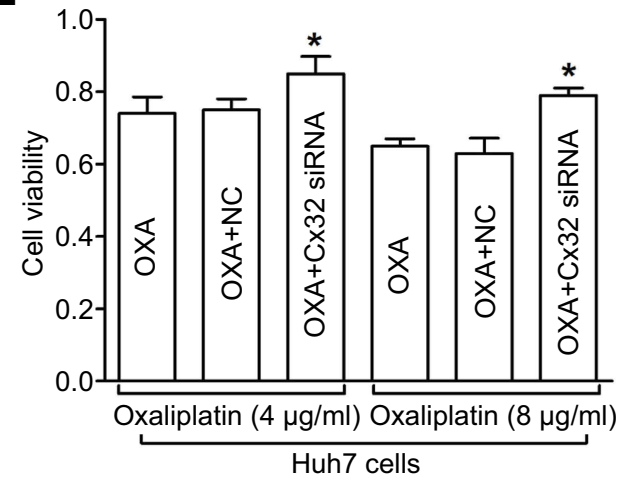

Figure 5 Depletion of Cx32 in parental Huh7 cells induces EMT and reduces chemosensitivity to OXA. (A) Western blot was conducted to detect the inhibitory effect of Cx32 siRNA in Huh7 cells. (B) Cell morphological changes of Cx32 downregulated Huh7 cells as assessed by microscopy. (C) Decreased expression of E-cadherin but increased expression levels of Vimentin and Snail were found upon Cx32 silencing in Huh7 cells, as shown by Western blot. (D) Invasive ability was enhanced by Cx32 knockdown in Huh7 cells as assessed by the transwell invasion assay. (E) The MTT assay was performed to measure cell growth in Huh7 cells transfected with Cx32 siRNA 3. $* * P<0.01$ vs $N C$ (D), and $* P<0.05$ vs either OXA treatment in Huh7 cells or OXA treatment in Huh7 cells transfected with control siRNA (E).

Abbreviations: Cx, connexin; EMT, epithelial-mesenchymal transition; NC, negative control; OXA, oxaliplatin.

Therefore, EMT is considered an important target for reversing tumor resistance. ${ }^{33,34}$ Therefore, we investigated the relationship between OXA resistance and EMT in HCC cells. Consistent with the above findings, we successfully obtained various OR HCC cell lines by chronic long-term induction of OXA, which also underwent EMT changes. Combined with our previous findings on GEM resistance in HCC cells, ${ }^{8}$ we consider that EMT may be a common molecular event after HCC cells acquire resistance to various chemotherapeutic drugs.

Cx proteins are implicated in a variety of biological events through GJ-dependent or non-GJ-dependent pathways. ${ }^{10}$ It was reported that overexpression of $\mathrm{Cx} 26$ or $\mathrm{Cx} 43$ inhibits the proliferation of breast cancer cells in vitro as well as tumorigenicity in vivo and promotes the cellular transition from mesenchymal to epithelial. ${ }^{35}$ Co-downregulation of $\mathrm{Cx}$ and E-cadherin was detected in NSCLC tissues, and overexpression of $\mathrm{Cx} 43$ in lung cancer cells recruits E-cadherin to the cell membrane. ${ }^{36} \mathrm{Cx} 43$ also reverses the malignant phenotypes of glioma stem cells, in association with the upregulation of E-cadherin and its various downstream transcriptional target molecules. ${ }^{37}$ Since E-cadherin downregulation or deletion is an important promoter of the EMT process in tumor cells, ${ }^{38}$ it was not difficult to speculate that $\mathrm{Cx}$ proteins may 
A
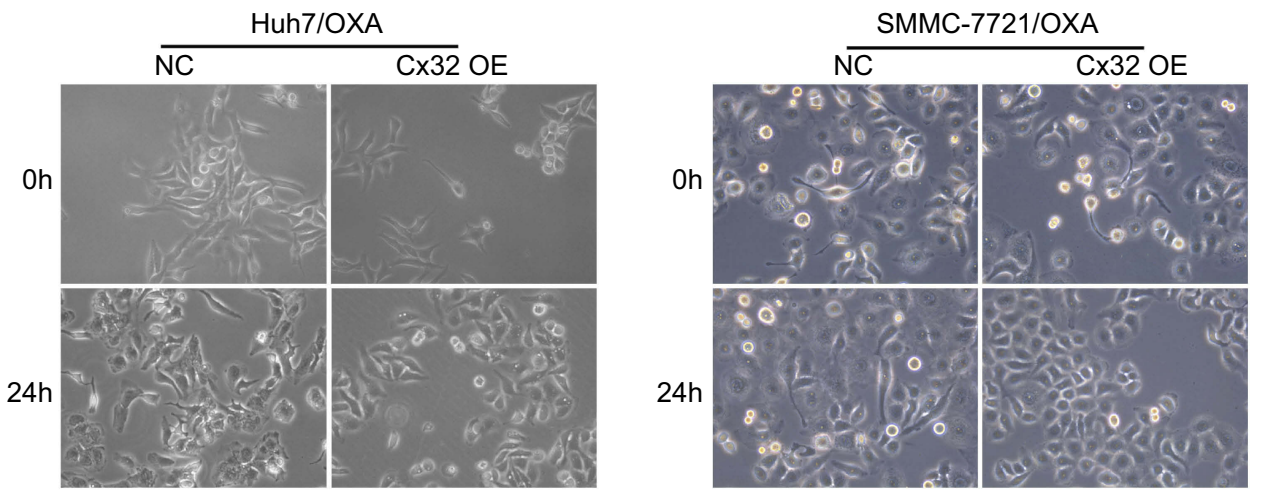

B
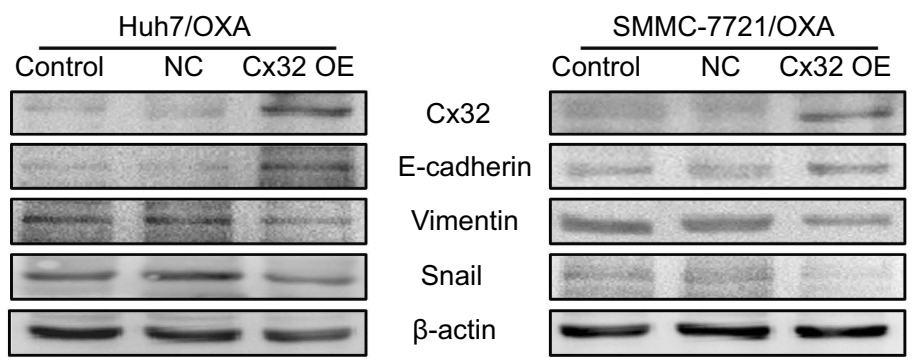

C
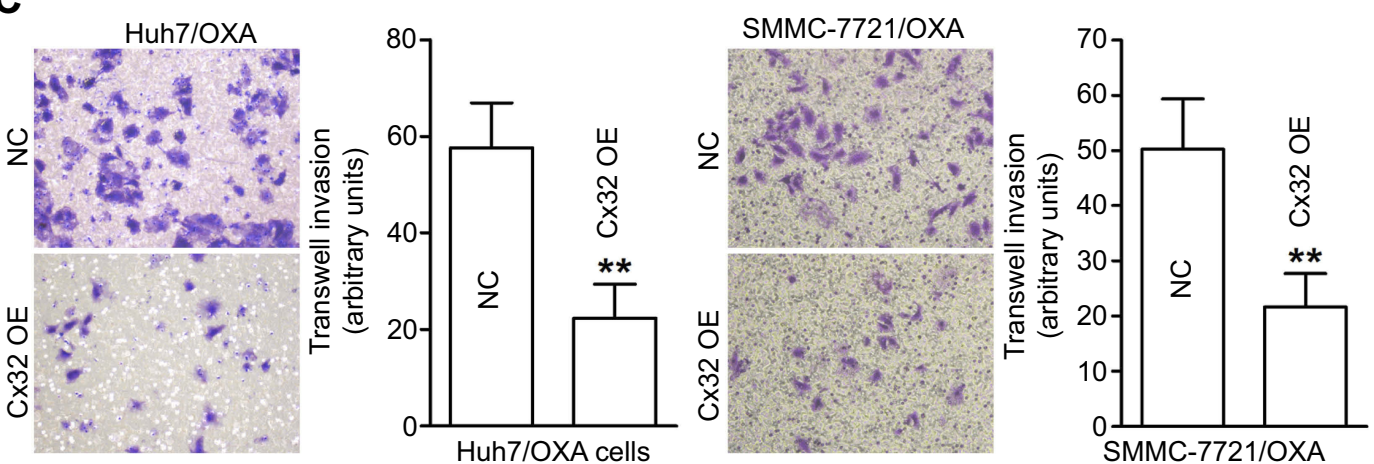

D
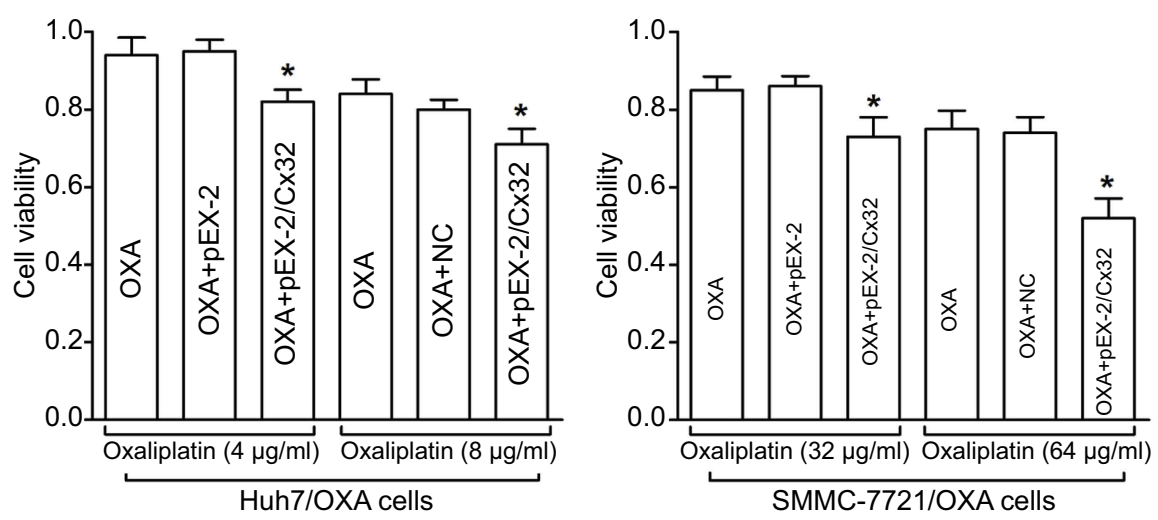

Figure 6 Overexpression of Cx32 reverses the EMT phenotype and enhances chemosensitivity to OXA in OR HCC cells. (A) Cell morphological changes of Huh7/OXA and SMMC-772I/OXA cells transfected with PEX-2/hCx32. (B) Increased expression of E-cadherin and decreased Vimentin and Snail levels were detected in Huh7/OXA and SMMC-772I/OXA cells following Cx32 overexpression, as shown by Western blot. (C) Upregulation of Cx32 suppressed cell invasion in OR HCC cells Huh7/OXA and SMMC-772I/OXA, as assessed by the transwell invasion assay. (D) Huh7/OXA and SMMC-772I/OXA showed increased chemosensitivity to OXA after CX32 overexpression by gene transfection, as determined by the MTT assay. Huh7/OXA and SMMC-772I/OXA cells were cultured in cell growth medium containing $4 \mu \mathrm{g} / \mathrm{mL}$ and $8 \mu \mathrm{g} /$ $\mathrm{mL}$ OXA. $* * P<0.01$ vs $N C(\mathbf{C})$, and $* P<0.05$ vs either OXA treatment or OXA treatment in OR cells transfected with control plasmid (D).

Abbreviations: Cx, connexin; EMT, epithelial-mesenchymal transition; NC, negative control; OE, overexpression; OR, OXA-resistant; OXA, oxaliplatin. 
A

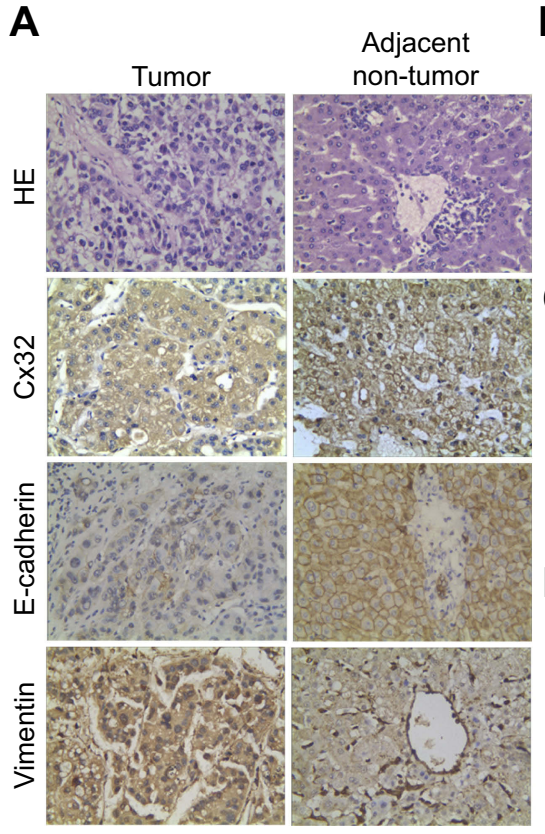

B

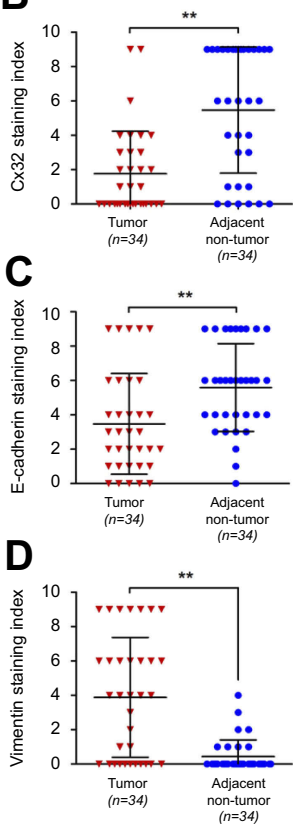

Figure 7 Expression levels of $\mathrm{C} \times 32$, E-cadherin and Vimentin in $\mathrm{HCC}$ and matched adjacent nontumor (ANT) tissues. (A) Staining of Cx32, E-cadherin, and Vimentin was performed by immunohistochemistry, and representative images are shown. While Cx32 was weakly stained and mainly located in the cytoplasm in HCC tissues, Cx32 signals were distributed abundantly and linearly on the membrane in ANT tissues. Remarkably reduced membrane staining of E-cadherin was observed in HCC tissues compared with adjacent noncancerous normal liver tissues. HCC tissues showed strong staining of Vimentin in the cytoplasm, while ANT tissues had weak or no Vimentin expression (original magnification, $\times 400$ ). (B-D) The staining indexes (SI) of Cx32 (B) and E-cadherin (C) were significantly lower, but that of Vimentin (D) was markedly higher in $\mathrm{HCC}$ tissues compared with normal paired samples. ${ }^{*} * P<0.01$.

Abbreviations: ANT, adjacent nontumor; Cx, connexin; HCC, hepatocellular carcinoma

have the potential to regulate EMT. A series of recent studies have confirmed this hypothesis. First, in cisplatin-resistant lung adenocarcinoma A549/CDDP cells, Cx43 could modulate EMT. ${ }^{26}$ Subsequent findings regarding doxorubicin resistance in $\mathrm{HCC}$ cells revealed that $\mathrm{Cx} 32$ is an important regulator of doxorubicin-induced $\mathrm{EMT}^{28}$ In addition, we have demonstrated that $\mathrm{Cx} 32$ is downregulated in HCC cells during hepatocarcinogenesis, and decreased $\mathrm{Cx} 32$ induces
EMT by activating the Wnt/ $\beta$-catenin/Snail pathway and confers high invasion and metastasis characteristics in HCC cells. ${ }^{18}$ In view of the importance of OXA in systemic chemotherapy for advanced HCC and the close relationship between EMT and chemoresistance, we aimed to assess the molecular mechanisms underlying EMT-related OXA resistance in HCC cells and explore whether this process is associated with $\mathrm{Cx}$ regulation. We first observed different patterns of various $\mathrm{Cx}$ proteins accompanied by EMT acquisition in OR HCC cells, with no significant difference in Cx43 expression, while $\mathrm{C} \times 26$ and $\mathrm{C} \times 32$ were downregulated; the difference in Cx32 expression was the most obvious. These results were confirmed in different HCC parental cell lines and the corresponding OR cells. We hypothesized that such discrepancy may be related to the different roles of $\mathrm{Cx}$ proteins in HCC. Three major Cxs, including Cx26, Cx32, and Cx43, were reported to be expressed in human and rat livers. Since $\mathrm{Cx} 32$ is the major subtype protein constituting the functional GJ in the liver, ${ }^{12}$ studies assessing Cxs in HCC have been more focused on $\mathrm{Cx} 32$ in recent years. Our findings also supported the notion that $\mathrm{C} \times 32$ may be a very important player in the process of acquired drug resistance to OXA in HCC. Induction of EMT by $\mathrm{Cx} 32$ inhibition in HCC parental cell lines, including HepG2 and SMMC-7721 cells, was shown in our pioneer study. ${ }^{18}$ In the current work, we further assessed the role of $\mathrm{Cx} 32$ and found a $\mathrm{Cx} 32$ downregulation or loss in

Table 3 Correlation of $\mathrm{C} \times 32$ and Vimentin expression in 34 HCCs

\begin{tabular}{|l|l|l|l|l|l|}
\hline \multirow{2}{*}{ Cx32 } & \multicolumn{2}{|l|}{ Vimentin } & \multirow{2}{*}{ Total } & $\boldsymbol{r}$ & P-value \\
\cline { 2 - 4 } & - & + & & \\
\hline- & 4 & 16 & 20 & -0.448 & $0.008^{*}$ \\
+ & 9 & 5 & 14 & & \\
Total & 13 & 21 & 34 & & \\
\hline
\end{tabular}

Note: $* P<0.05$.

Abbreviations: Cx32, connexin 32; HCC, hepatocellular carcinoma.

Table 2 Expression of $\mathrm{Cx} 32$, E-cadherin, and Vimentin in HCC and matched adjacent nontumor tissues

\begin{tabular}{|l|l|l|l|l|l|l|l|l|l|l|l|l|}
\hline \multirow{2}{*}{ Variable } & \multicolumn{4}{|l|}{ HCC tissues $(\boldsymbol{n = 3 4})$} & \multicolumn{4}{|l|}{ Adjacent nontumor tissues (n=34) } & \\
\cline { 2 - 12 } & - & + & ++ & +++ & $\%$ & - & + & ++ & +++ & $\%$ & Z-value & P-value \\
\hline Cx32 & 20 & 7 & 5 & 2 & 41.2 & 5 & 2 & 12 & 15 & 85.3 & -4.714 & $0.000 *$ \\
E-cadherin & 10 & 10 & 9 & 5 & 70.6 & 2 & 5 & 18 & 9 & 94.1 & -2.972 & $0.003 *$ \\
Vimentin & 13 & 2 & 12 & 7 & 61.8 & 30 & 3 & 1 & 0 & 11.8 & -4.566 & $0.000 *$ \\
\hline
\end{tabular}

Note: $* P<0.05$ vs adjacent nontumor tissues.

Abbreviations: $\mathrm{C} \times 32$, connexin 32 ; HCC, hepatocellular carcinoma. 
OR HCC cells. On the contrary, upon overexpression of Cx32 by gene transfection in OR HCC cells, EMT was reverted and chemosensitivity to OXA was partially restored. We finally confirmed the associations of $\mathrm{Cx} 32$ with EMT markers in human HCC tissues. These results together suggested that downregulation of $\mathrm{Cx} 32$ may be an important molecular event in HCC cells acquiring drug resistance to OXA and the related EMT.

The chemosensitization effect of $\mathrm{Cx}$ on various cytotoxic drugs (eg, OXA) has been confirmed by several studies. $^{20,22,39}$ Although its exact mechanism of action remains not fully elucidated, research has focused on the following aspects: 1) The role of GJ-dependent communication functions. The GJ-mediated "bystander effect" has been proposed as a mechanism of cell death caused by distinct damage factors. ${ }^{40}$ That is, while damage factors such as cytotoxic drugs induce cell death or apoptosis, it may promote a certain death or injury signal. When this signal is small enough to be transmitted to adjacent cells through GJs, it causes adjacent cells to die, thereby expanding the cytotoxicity of the drug. 2) non-GJdependent hemi-channel effects. Six $\mathrm{Cx}$ proteins surround the central channel on the cell membrane to form a "hemichannel." A pair of hemi-channels on adjacent cells is docked by the carbon ends of their extracellular loops to form a whole GJ channel. The hemi-channel is also one of the signaling pathways by which small molecules are released outside the cell, leading to changes in the concentrations of intracellular ions (such as $\mathrm{Ca}^{2+}$ ) or small molecules (such as ATP), which are involved in the transduction of various intracellular signals. ${ }^{41} 3$ ) Exerting biological effects as an independent protein. Cx itself plays an important role in physiological and pathological processes such as cell growth, apoptosis, oncogenesis, tumor invasion, and metastasis by regulating intracellular signal transduction and possible downstream gene transcription. $^{42,43}$ This study provided evidence, for the first time, that $\mathrm{Cx} 32$ could partly restore chemosensitivity in OR HCC cells by reversing EMT. In this process, we speculate that the effect of Cx32 may be related to its own independent function, because immunofluorescence revealed that $\mathrm{Cx} 32$ was mostly localized in the cytoplasm and did not fulfill the conditions for assembly into GJs; only $\mathrm{Cx}$ localized on the cell membrane can form functional hemi-channels and GJ full channels. Studies have demonstrated an inhibitory effect of tumor growth by Cx26 or Cx43 overexpression in vivo; however, overexpressed $\mathrm{Cx}$ proteins accumulate in the cytoplasm and function through non-GJ-dependent mechanisms, including regulation of EMT and antiangiogenesis. ${ }^{35}$ The latter study, together with the present results, suggested that $\mathrm{Cx}$ proteins accumulated in the cytoplasm may play a unique and complex role in regulating a variety of biological effects.

\section{Conclusion}

In conclusion, the present study established the role of Cx32 in EMT occurrence in HCC cells resistant to OXA. We found downregulated $\mathrm{Cx} 32$ accompanied with mesenchymal phenotypic features in OR HCC cells and Cx32 upregulation in OR HCC cells could partly restore chemosensitivity to OXA by reversing EMT. Therefore, targeting Cx32 by recruiting or stimulating its expression could constitute a promising approach for overcoming chemoresistance toward effective treatment of advanced HCC.

\section{Consent for publication}

The publication of this study was approved by the ethics committee of the First Affiliated Hospital of Bengbu Medical College. Written informed consent was obtained from the patients or their immediate family members.

\section{Ethics approval}

The usage of patients' tissue samples in this study was approved by the ethics committee of the First Affiliated Hospital of Bengbu Medical College.

\section{Data sharing statement}

The data supporting the results in the manuscript can be obtained from the corresponding author based on reasonable request.

\section{Acknowledgments}

We thank Biochemical \& Medical Engineering Research Center of Anhui Province and Scientific Research Platform of Bengbu Medical College for instruments support. This work was supported by the National Natural Science Foundation of China (No. 81402514), and internal grant from the First Affiliated Hospital of Bengbu Medical College (No. Byyfykj201801).

\section{Disclosure}

The authors report no conflicts of interest in this work. 


\section{References}

1. Bray F, Ferlay J, Soerjomataram I, Siegel RL, Torre LA, Jemal A. Global cancer statistics 2018: GLOBOCAN estimates of incidence and mortality worldwide for 36 cancers in 185 countries. CA Cancer J Clin. 2018;68(6):394-424. doi:10.3322/caac.21492

2. Contratto M, Wu J. Targeted therapy or immunotherapy? Optimal treatment in hepatocellular carcinoma. World J Gastrointest Oncol. 2018;10(5):108-114. doi:10.4251/wjgo.v10.i5.108

3. Qin S, Bai Y, Lim HY, et al. Randomized, multicenter, open-label study of oxaliplatin plus fluorouracil/leucovorin versus doxorubicin as palliative chemotherapy in patients with advanced hepatocellular carcinoma from Asia. J Clin Oncol. 2013;31(28):3501-3508. doi:10.1200/JCO.2012.44.5643

4. Petrelli F, Coinu A, Borgonovo K, et al. Oxaliplatin-based chemotherapy: a new option in advanced hepatocellular carcinoma a systematic review and pooled analysis. Clin Oncol ( $R$ Coll Radiol). 2014;26(8):488-496. doi:10.1016/j.clon.2014.04.031

5. Martin LP, Hamilton TC, Schilder RJ. Platinum resistance: the role of DNA repair pathways. Clin Cancer Res. 2008;14(5):1291-1295. doi:10.1158/1078-0432.CCR-07-2238

6. Brozovic A. The relationship between platinum drug resistance and epithelial-mesenchymal transition. Arch Toxicol. 2017;91 (2):605-619. doi:10.1007/s00204-016-1912-7

7. Singh A, Settleman J. EMT, cancer stem cells and drug resistance: an emerging axis of evil in the war on cancer. Oncogene. 2010;29 (34):4741-4751. doi:10.1038/onc.2010.215

8. Wang R, Li Y, Hou Y, et al. The PDGF-D/miR-106a/Twistl pathway orchestrates epithelial-mesenchymal transition in gemcitabine resistance hepatoma cells. Oncotarget. 2015;6(9):7000-7010. doi:10.18632 oncotarget.3193

9. Sleeman JP, Thiery JP. SnapShot: the epithelial-mesenchymal transition. Cell. 2011;145(1):162 e161. doi:10.1016/j.cell.2011.03.029

10. Aasen T. Connexins: junctional and non-junctional modulators of proliferation. Cell Tissue Res. 2015;360(3):685-699. doi:10.1007/ s00441-014-2078-3

11. Graham SV, Jiang JX, Mesnil M. Connexins and pannexins: important players in tumorigenesis, metastasis and potential therapeutics. Int J Mol Sci. 2018;19(6). doi:10.3390/ijms 19061645

12. Maes M, Decrock E, Cogliati B, et al. Connexin and pannexin (hemi) channels in the liver. Front Physiol. 2014;4:405. doi:10.3389/ fphys.2013.00405

13. King TJ, Lampe PD. The gap junction protein connexin32 is a mouse lung tumor suppressor. Cancer Res. 2004;64(20):7191-7196. doi:10.1158/0008-5472.CAN-04-0624

14. Fujimoto E, Sato H, Shirai S, et al. Connexin32 as a tumor suppressor gene in a metastatic renal cell carcinoma cell line. Oncogene. 2005;24(22):3684-3690. doi:10.1038/sj.onc.1208430

15. Nakashima Y, Ono T, Yamanoi A, El-Assal ON, Kohno H, Nagasue N. Expression of gap junction protein connexin 32 in chronic hepatitis, liver cirrhosis, and hepatocellular carcinoma. J Gastroenterol. 2004;39 (8):763-768. doi:10.1007/s00535-003-1386-2

16. Edwards GO, Jondhale S, Chen T, Chipman JK. A quantitative inverse relationship between connexin 32 expression and cell proliferation in a rat hepatoma cell line. Toxicology. 2008;253(1-3):46-52. doi: $10.1016 /$ j.tox.2008.08.010

17. Zhao B, Zhao W, Wang Y, et al. Connexin32 regulates hepatoma cell metastasis and proliferation via the p53 and Akt pathways. Oncotarget. 2015;6(12):10116-10133. doi:10.18632/oncotarget.2687

18. Yang Y, Zhang N, Zhu J, et al. Downregulated connexin32 promotes EMT through the Wnt/beta-catenin pathway by targeting Snail expression in hepatocellular carcinoma. Int $J$ Oncol. 2017;50 (6):1977-1988. doi:10.3892/ijo.2017.3985
19. Wang Q, You T, Yuan D, et al. Cisplatin and oxaliplatin inhibit gap junctional communication by direct action and by reduction of connexin expression, thereby counteracting cytotoxic efficacy. J Pharmacol Exp Ther. 2010;333(3):903-911. doi:10.1124/jpet.109.165274

20. Sato A, Sekine M, Kobayashi M, Virgona N, Ota M, Yano T. Induction of the connexin 32 gene by epigallocatechin-3-gallate potentiates vinblastine-induced cytotoxicity in human renal carcinoma cells. Chemotherapy. 2013;59(3):192-199. doi:10.1159/000354715

21. Yang AD, Fan F, Camp ER, et al. Chronic oxaliplatin resistance induces epithelial-to-mesenchymal transition in colorectal cancer cell lines. Clin Cancer Res. 2006;12(14 Pt 1):4147-4153. doi:10.1158/1078-0432.CCR-06-0038

22. Yang Y, Zhu J, Zhang N, et al. Impaired gap junctions in human hepatocellular carcinoma limit intrinsic oxaliplatin chemosensitivity: a key role of connexin 26. Int J Oncol. 2016;48(2):703-713. doi:10.3892/ijo.2015.3266

23. Cauchy F, Soubrane O, Belghiti J. Liver resection for HCC: patient's selection and controversial scenarios. Best Pract Res Clin Gastroenterol. 2014;28(5):881-896. doi:10.1016/j.bpg.2014.08.013

24. Virag P, Fischer-Fodor E, Perde-Schrepler M, et al. Oxaliplatin induces different cellular and molecular chemoresistance patterns in colorectal cancer cell lines of identical origins. BMC Genomics. 2013;14:480. doi:10.1186/1471-2164-14-181

25. Li QQ, Xu JD, Wang WJ, et al. Twist1-mediated adriamycin-induced epithelial-mesenchymal transition relates to multidrug resistance and invasive potential in breast cancer cells. Clin Cancer Res. 2009;15 (8):2657-2665. doi:10.1158/1078-0432.CCR-08-2372

26. Yu M, Zhang C, Li L, Dong S, Zhang N, Tong X. Cx43 reverses the resistance of A549 lung adenocarcinoma cells to cisplatin by inhibiting EMT. Oncol Rep. 2014;31(6):2751-2758. doi:10.3892/or.2014.3163

27. Ren J, Chen Y, Song H, Chen L, Wang R. Inhibition of ZEB1 reverses EMT and chemoresistance in docetaxel-resistant human lung adenocarcinoma cell line. $J$ Cell Biochem. 2013;114 (6): 1395-1403. doi:10.1002/jcb.24481

28. Yu M, Han G, Qi B, Wu X. Cx32 reverses epithelial-mesenchymal transition in doxorubicin-resistant hepatocellular carcinoma. Oncol Rep. 2017;37(4):2121-2128. doi:10.3892/or.2017.5462

29. Wang J, Zhou F, Li Y, et al. Cdc20 overexpression is involved in temozolomide-resistant glioma cells with epithelial-mesenchymal transition. Cell Cycle. 2017;16(24):2355-2365. doi:10.1080/ 15384101.2017.1388972

30. Cao L, Wan Q, Li F, Tang CE. MiR-363 inhibits cisplatin chemoresistance of epithelial ovarian cancer by regulating snail-induced epithelial-mesenchymal transition. BMB Rep. 2018;51(9):456-461.

31. Witta SE, Gemmill RM, Hirsch FR, et al. Restoring E-cadherin expression increases sensitivity to epidermal growth factor receptor inhibitors in lung cancer cell lines. Cancer Res. 2006;66(2):944-950. doi:10.1158/0008-5472.CAN-05-1988

32. Chang TH, Tsai MF, Su KY, et al. Slug confers resistance to the epidermal growth factor receptor tyrosine kinase inhibitor. Am J Respir Crit Care Med. 2011;183(8):1071-1079. doi:10.1164/rccm.201009-1440OC

33. van Staalduinen J, Baker D, Ten Dijke P, van Dam H. Epithelialmesenchymal-transition-inducing transcription factors: new targets for tackling chemoresistance in cancer? Oncogene. 2018. doi:10.1038/s41388-018-0378-x

34. Du B, Shim JS. Targeting Epithelial-Mesenchymal Transition (EMT) to overcome drug resistance in cancer. Molecules. 2016;21(7):965. doi: $10.3390 /$ molecules 21070965

35. McLachlan E, Shao Q, Wang HL, Langlois S, Laird DW. Connexins act as tumor suppressors in three-dimensional mammary cell organoids by regulating differentiation and angiogenesis. Cancer Res. 2006;66 (20):9886-9894. doi:10.1158/0008-5472.CAN-05-4302

36. Xu HT, Li QC, Zhang YX, et al. Connexin 43 recruits E-cadherin expression and inhibits the malignant behaviour of lung cancer cells. Folia Histochem Cytobiol. 2008;46(3):315-321. doi:10.2478/v10042-008-0057-9 
37. Yu SC, Xiao HL, Jiang XF, et al. Connexin 43 reverses malignant phenotypes of glioma stem cells by modulating E-cadherin. Stem Cells. 2012;30(2):108-120. doi:10.1002/stem.1685

38. Gravdal K, Halvorsen OJ, Haukaas SA, Akslen LA. A switch from E-cadherin to $\mathrm{N}$-cadherin expression indicates epithelial to mesenchymal transition and is of strong and independent importance for the progress of prostate cancer. Clin Cancer Res. 2007;13 (23):7003-7011. doi:10.1158/1078-0432.CCR-07-1263

39. Wang SQ, Zhang SW, Zhang CZ, Zhao ZY, Wang YJ. Connexin 43 enhances oxaliplatin cytotoxicity in colorectal cancer cell lines. Cell Mol Biol (Noisy-le-grand). 2017;63(4):53-58. doi:10.14715/cmb/2017.63.4.9

40. Arora S, Heyza JR, Chalfin EC, Ruch RJ, Patrick SM. Gap junction intercellular communication positively regulates cisplatin toxicity by inducing DNA damage through bystander signaling. Cancers (Basel). 2018;10(10):368. doi:10.3390/cancers 10100368
41. Quist AP, Rhee SK, Lin H, Lal R. Physiological role of gap-junctional hemichannels. Extracellular calcium-dependent isosmotic volume regulation. J Cell Biol. 2000;148(5): 1063-1074.

42. Zhou JZ, Jiang JX. Gap junction and hemichannel-independent actions of connexins on cell and tissue functions-an update. FEBS Lett. 2014;588(8):1186-1192. doi:10.1016/j.febslet. 2014.01.001

43. Yu M, Zou Q, Wu X, Han G, Tong X. Connexin 32 affects doxorubicin resistance in hepatocellular carcinoma cells mediated by Src/ FAK signaling pathway. Biomed Pharmacother. 2017;95:1844-1852. doi:10.1016/j.biopha.2017.09.065

\section{Publish your work in this journal}

Cancer Management and Research is an international, peer-reviewed open access journal focusing on cancer research and the optimal use of preventative and integrated treatment interventions to achieve improved outcomes, enhanced survival and quality of life for the cancer patient.
The manuscript management system is completely online and includes a very quick and fair peer-review system, which is all easy to use. Visit http://www.dovepress.com/testimonials.php to read real quotes from published authors. 